\title{
Vehicle-to-Vehicle Radio Channel Characteristics for Congestion Scenario in Dense Urban Region at 5.9 GHz
}

\author{
Yishui Shui $\mathbb{D}^{1},{ }^{1}$ Fang Li $\mathbb{D},{ }^{2}$ Junyi Yu $\mathbb{D},{ }^{2}$ Wei Chen $\mathbb{D},{ }^{2}$ Changzhen Li $\mathbb{D},{ }^{2}$ Kun Yang $\mathbb{D},{ }^{3}$ \\ and Fuxing Chang ${ }^{1}$
}

${ }^{1}$ School of Information Engineering, Wuhan University of Technology, Wuhan, Hubei 430070, China

${ }^{2}$ School of Automation, Wuhan University of Technology, Wuhan Hubei 430070, China

${ }^{3}$ Super Radio AS, Oslo, Norway

Correspondence should be addressed to Wei Chen; greatchen911119@sohu.com

Received 14 June 2017; Revised 10 November 2017; Accepted 7 December 2017; Published 1 April 2018

Academic Editor: Ahmad Safaai-Jazi

Copyright (C) 2018 Yishui Shui et al. This is an open access article distributed under the Creative Commons Attribution License, which permits unrestricted use, distribution, and reproduction in any medium, provided the original work is properly cited.

\begin{abstract}
This paper reports the results of a car-following measurement of the wireless propagation channel at $5.9 \mathrm{GHz}$ on a seriously congested urban road in Wuhan, China. The small-scale amplitude-fading distribution was determined to be a Ricean distribution using the Akaike information criterion. This result shows that this car-following scenario can be regarded as a lineof-sight radio channel. Moreover, the statistical $K$-factor features follow a Gaussian distribution. According to the power delay profile and average power delay profile, we found that street buildings in this dense urban environment contributed to very strong reflection phenomena. The impact of a powerful reflection is analyzed through path loss, delay, and Doppler spreads in the channel statistical properties. In the frequency domain, we observe a U-shape delay-Doppler spectrum that proved that the dense urban scenario consists of scattering channels. All these results are summarized in tabular form that will be useful in the modeling of vehicle-to-vehicle wireless communication systems.
\end{abstract}

\section{Introduction}

As mobile communications and wireless Internet technology continue to develop, the combination of smart phones and wireless broadband has greatly facilitated our life. With the increasing demand for the Internet of Things, more researchers have begun to focus on intelligent transportation systems (ITSs) [1]. In the future, each car will have an intelligent terminal system that will enable it to obtain real-time information from the Internet of Vehicles for optimizing its behavior and trips [2]. Among all of the technologies in an ITS, vehicle-to-vehicle $(\mathrm{V} 2 \mathrm{~V})$ wireless communication is an important part of the vehicle networking system. Thus, the United States Federal Communication Commission specifically allocated $5.9 \mathrm{GHz}$ for ITSs in 1999 [3].

To ensure effective information transmission in the vehicle network, a large number of studies analyzing the channel characteristics of vehicle communications have been performed. The authors of [4] performed measurements of a vehicle passing through an overpass and analyzed the rootmean-square (RMS) delay spread and path loss. In [5], aboveground parking garages were investigated using multiple measurements in different scenarios. In addition, [6] studied the path loss, small-scale fading, shadowing effect, and crosscorrelation that occurs when a large bus is located between two compact cars. The authors of [7] focused on tunnels and studied the effect of occlusion in the environment on radio signal transmission. Using $4 \times 45.2 \mathrm{GHz}$ multipleinput multiple-output measurements, [8] determined the delay-Doppler spectrum in a city environment. Reference [9] studied $\mathrm{V} 2 \mathrm{~V}$ communication at merging lanes on the highway, and [10] used local scattering functions to deal with measured data for several urban scenarios at $5.2 \mathrm{GHz}$, studying delay and Doppler spreads. Reference [11] researched path loss models for four slope scenarios. The characteristics of the $K$-factor, which is an important parameter of the Ricean distribution, were studied in [12-16]. Finally, [17] studied wireless channel properties on high-speed railways. 
It introduced best-fit small-scale amplitude-fading distribution and Ricean $K$-factor analysis in detail.

Many V2V measurement scenarios were provided in [18], which includes four street-crossing scenarios in suburban and urban areas as well as scenarios for highways, merging lanes, tunnels, bridges, traffic congestion, and vehicles approaching traffic jams. However, because it is a common situation in dense urban regions, traffic congestion needs a more comprehensive analysis. Moreover, current research on vehicle wireless communications are mainly conducted in Europe and American environments [19-21], specifically for the ITS frequency bands $(5.85-5.925 \mathrm{GHz})$. There is a lack of sufficient V2X channel measurements in Asian areas, where the population density, vehicles, and layout of the streets and buildings are different from those of Europe and American cities (e.g., in the congestion scenario in this study, vehicle speeds are around $0-5 \mathrm{~m} / \mathrm{s}$, which is much slower than those in [18], which are $4.2-8.3 \mathrm{~m} / \mathrm{s}$ ). To fill these gaps, this study carried out a car-following $\mathrm{V} 2 \mathrm{~V}$ measurement at $5.9 \mathrm{GHz}$ on a seriously congested dense urban road in Wuhan, China. The channel estimation results and statistical analysis are presented for power, delay, and frequency domains.

The remainder of this paper is arranged as follows: Section 2 presents the measurement environment, including the scenario overview, equipment setup, and measurement description. Next, small-scale amplitude fading and Ricean $K$-factors are analyzed in Section 3.1. The power-delay profile (PDP) and path loss as well as the impact of powerful reflection phenomena on the energy domain and statistics are shown in Sections 3.2 and 3.3, respectively. Section 3.4 provides the Doppler domain analysis. Finally, Section 4 presents the conclusions.

\section{Measurement Experiments}

2.1. Scenario Overview. We chose the Luoshi Road in Wuhan as the measurement area. The traffic situation on this road is very complex. This road section is not only an important node of the second ring road but also includes an intersection for South Luoshi Road and Xiongchu Road (shown in Figure 1(a)). During rush hour, traffic flow from the west, south, and east gather at the northern edge of the area to enter the dense urban regions of Wuhan.

A trapezoid is generated where the lanes decrease from five to three, as shown in Figure 1(b). This shape leads to a bottleneck, which can easily cause congestion when the traffic flow increases. Furthermore, this road has another bottleneck before it (about $500 \mathrm{~m}$ away). As shown in Figure 1(c), a large number of vehicles change lanes here. Vehicle lane-changing behaviors cause cars to decelerate, which leads to another bottleneck. In this investigation, we found that this section is normally always congested except for late at night. Sometimes a traffic queue can be as long as $2 \mathrm{~km}$. In addition, this section is surrounded by numerous tall buildings on the eastern and western sides. Thus, this area is a complex dense urban environment. Note that there are large metal signs over the street and overpasses crossing the street, as shown in Figure 1(b). All this infrastructure leads to complex reflection phenomena.

\subsection{Equipment Setup and Measurement Description}

2.2.1. Equipment Setup. A Fiat and Volkswagen on which omni antennas were mounted were used as the test cars. The Fiat carried the transmitter (TX) and the Volkswagen carried the receiver (RX), as shown in Figures 2(a) and 2(b), respectively. The $\mathrm{V} 2 \mathrm{~V}$ channel was measured using the Super Radio AS TDM channel sounder. A chirp signal with a bandwidth of $100 \mathrm{MHz}$ was emitted at $5.9 \mathrm{GHz}$. Our test system is powered by an uninterruptible power supply and uses a CSGPS-38BH global positioning system (GPS) connected to the channel sounder. Measurement data, formatted as a time-varying channel transfer function $H(f, t)$ and GPS information, were collected and stored on a laptop in real time. Table 1 gives the details of the measurement parameters.

2.2.2. Measurement Description. Our measurements were performed at $30^{\circ} 30^{\prime} 52.75^{\prime \prime} \mathrm{N} 114^{\circ} 20^{\prime} 40.99^{\prime \prime} \mathrm{E}$. The measurement duration was 109 s. Figure 3 shows the test route and speed of the measurement vehicles. As recorded on video, the two cars started in different lanes. They then merged into one lane after $70 \mathrm{~s}$. During the test process, the TX vehicle remained in front of the RX vehicle. As shown in Figure 3, a huge building was located along the measurement route on the eastern side (at about $30 \mathrm{~m}$ ). The velocities of TX and RX were maintained at a low level $(0-5 \mathrm{~m} / \mathrm{s})$ most of the time. The two cars traveled about $300 \mathrm{~m}$ in this congested section during the measurement.

\section{Channel Estimation and Result Analysis}

3.1. LOS Condition Determination and Ricean K-Factor Analysis. V2V wireless channel parameters have timevarying and nonstationary characteristics due to the dynamic changes of scatterers and high-speed movement of the transmitting and receiving stations [22]. To estimate the features of the wireless channel parameters, one solution is to set a quasi-stationary window for the $\mathrm{V} 2 \mathrm{~V}$ wireless channel parameter estimation assuming wide-sense stationary and uncorrelated scatterers (WSSUS) $[6,17,23]$. In this study, a sliding window of 10 wavelengths was used, and the radio channel can be treated as static in each window. The acquisition of the large-scale fading characteristics in the following text and the estimation of the small-scale features in Sections 3.2 and 3.3 are both based on it.

Akaike information criteria (AIC) algorithm is an algorithm that measures the relative fitness of a statistical model. It is commonly used to select a distribution model $[24,25]$. The small-scale amplitude-fading distribution with the smallest AIC value corresponds to the best matching model [26]. Ricean, Nakagami-m, Weibull, Lognormal, and Rayleigh distributions were considered as candidate distributions [22, 27-30].

In Figure 4, the biggest value of the Akaike weight for a model indicates the distribution of the model that best matches the data. Figure 4 shows that the Ricean distribution (97.87\%) best fits this car-following congestion scenario. The scores for the Nakagami-m and Weibull distributions are 


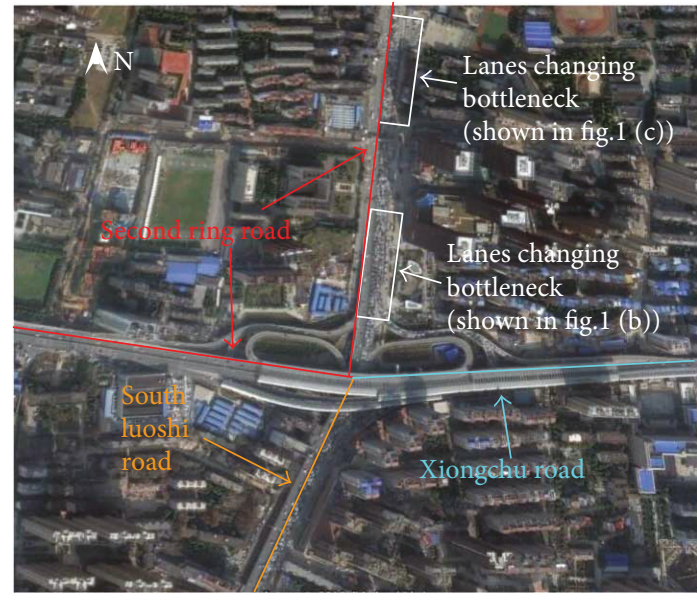

(a)

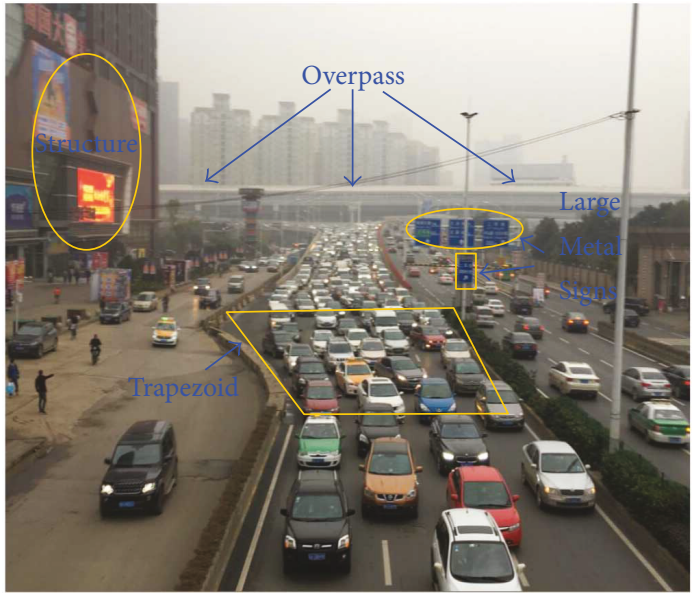

(b)

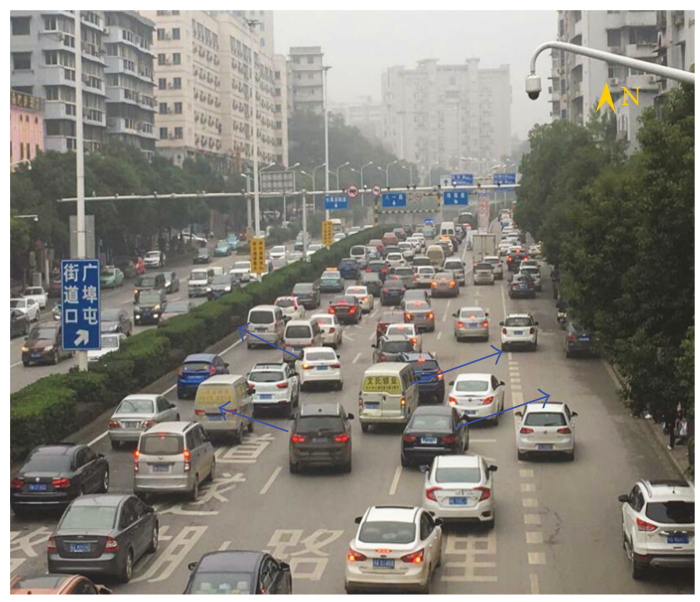

(c)

FIgURE 1: (a) Top view of the terrain; (b) lane-reduction bottleneck; (c) lane-change bottleneck.

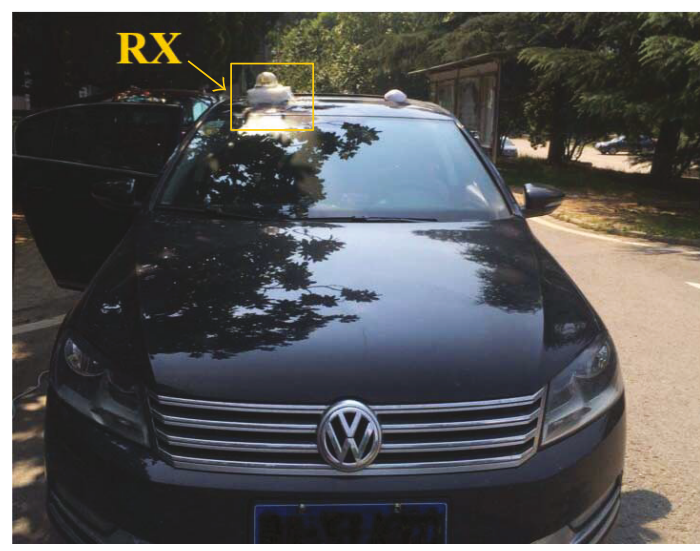

(a)

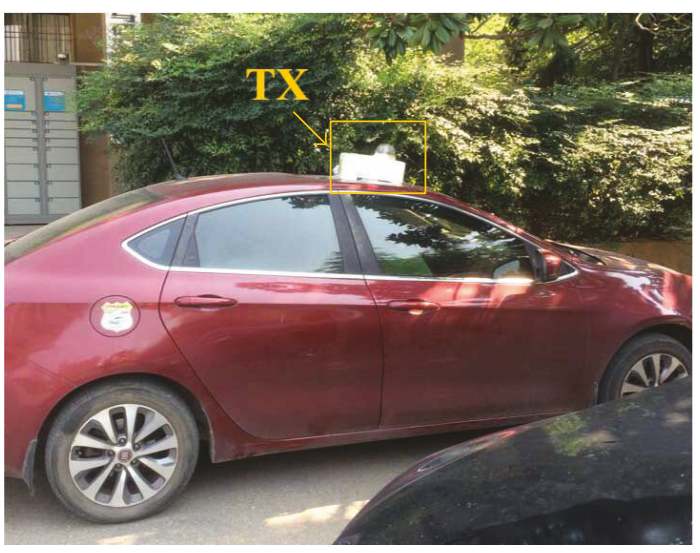

(b)

FIGURE 2: Measurement vehicles.

only $1.42 \%$ and $0.71 \%$, respectively. The $K$-factor is an important parameter of the Ricean distribution [31] and is the ratio of the energy of the line-of-sight (LOS) path $\rho^{2}$ to the energy of all other reflection paths $2 \sigma^{2}[23,32]$. As shown in Figure 5(a), the values of the $K$-factor are positive most of the time, which proves that this radio channel is a LOS channel. The cumulative distribution function (CDF) of the $K$ factor values is shown in Figure 5(b). A Gaussian distribution with a mean of 4.53 and standard deviation of 2.45 matches well with the measured data. Note that the values of the $K$ - 
TABLE 1: Measurement parameters.

\begin{tabular}{lc}
\hline Parameters & Values \\
\hline Center frequency & $5.9 \mathrm{GHz}$ \\
Bandwidth & $100 \mathrm{MHz}$ \\
Chirp interval & $517.2 \mu \mathrm{s}$ \\
Delay resolution & $10 \mathrm{~ns}$ \\
Samples per chirp & 2560 \\
Chirps per s & 1933 \\
TX power & $16 \mathrm{dBm}$ \\
TX gain & $2 \mathrm{dBi}$ \\
RX gain & $2 \mathrm{dBi}$ \\
TX height & $1.57 \mathrm{~m}$ \\
RX height & $1.50 \mathrm{~m}$ \\
Cable loss & $6 \mathrm{~dB}$ \\
Maximum TX-RX distance & $20.5 \mathrm{~m}$ \\
Maximum relative speed & $2.35 \mathrm{~m} / \mathrm{s}$ \\
Temperature & $36 \sim 38^{\circ} \mathrm{C}$ \\
Humidity & $35 \% \mathrm{RH}$ \\
\hline
\end{tabular}

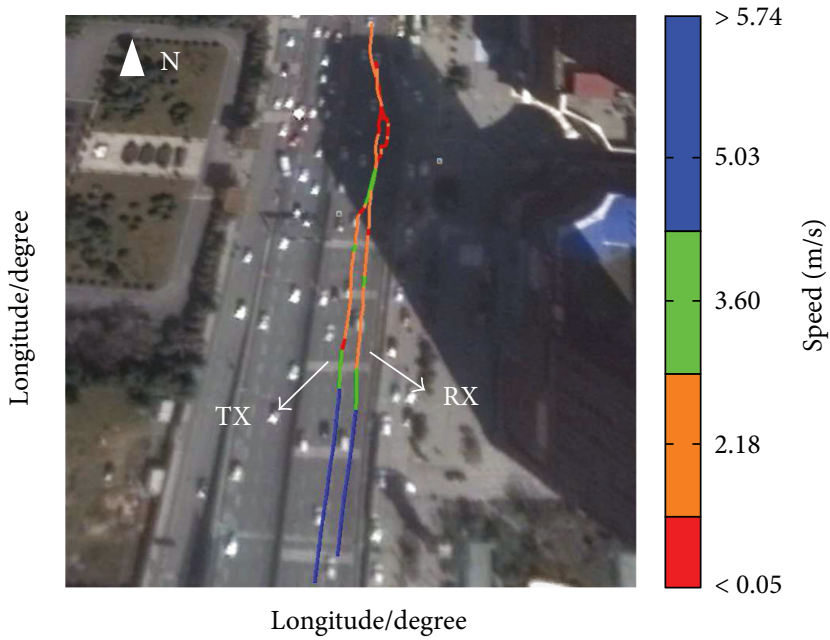

FIGURE 3: Measurement overview.

factor decrease sharply from 8 to $-4 \mathrm{~dB}$ around $42 \mathrm{~s}$. The following analysis in Section 3.2 tells us that this phenomenon is due to a very strong reflection path from a building on the street (shown in Figure 6). Because this building is located at a specific position close to the two measurement cars, its surface causes a quite powerful reflection path (shown in Figure 7). This situation contributes to a higher diffuse energy $2 \sigma^{2}$. Moreover, we also observe that another dip appears at around $80 \mathrm{~s}$. According to the video at $80 \mathrm{~s}$, this was caused by other vehicles moving between the TX and RX vehicles, which blocked the signal transmission and caused an obstructed line of sight (OLOS) phenomenon [33].

The above analysis leads to the following conclusions. Strong reflections occurring in a dense urban area will result in negative $K$-factor values in the LOS scenario. Furthermore, the $K$-factors follow a normal distribution in the carfollowing LOS dense urban-congestion scenario.

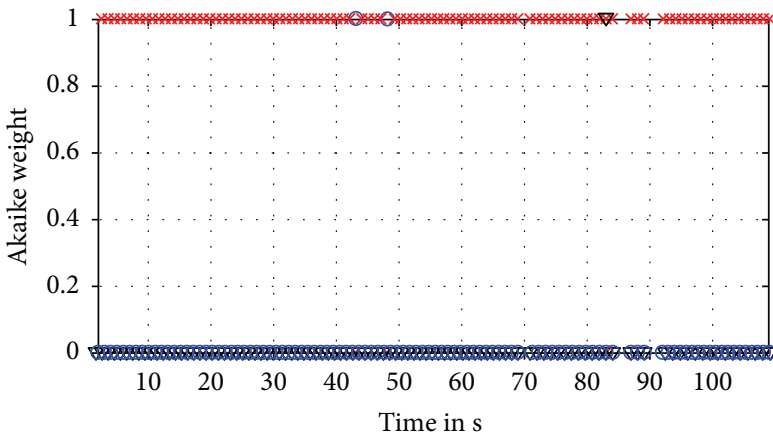

○ Denotes nakagami-m distribution

$\times$ Denotes rician distribution

$\nabla$ Denotes weibull distribution

Figure 4: Best-fit distribution of fades.

3.2. Power-Delay Profile and Path Loss. In this study, we analyzed the channel characteristics under the WSSUS assumption mentioned in Section 3.1. WSSUS model has uncorrelated characteristics in the delay domain $\tau$ and Doppler shift domain $v$; meanwhile, it has wide-sense stationary characteristics in the time domain $t$ and the frequency domain $f$ [23]. The time-varying instantaneous PDP of $P(t, \tau)$ in $t$ of $(1)$ is derived for each time sample of a chirp.

$$
P(t, \tau)=|h(t, \tau)|^{2}=\sum_{i}^{N}\left|a_{i}(t)\right|^{2} \delta\left(\tau-\tau_{i}\right) .
$$

Here, in $(1), h(t, \tau)$ is the complex time-varying channel impulse response derived by an inverse Fourier transform of a channel transfer function $H(f, t) . a_{i}$ denotes the complex coefficient of each delay path, which changes over time, and $\tau_{i}$ is the excess delay of the $i$ th path [23].

Under the WSSUS model, channel can be represented as a tapped delay line, where the coefficients multiplying the output from each tap varies with time. In (1), each of the $N$ components correspond to a set of closely spaced multipath components. This model is completely deterministic only when the arrival signals are made up of complete resolved echoes. However, the receiver could not resolve all multipath components. In this case, each complex coefficient $a_{i}(t)$ represents the sum of several fading multipath components [23].

The averaged power delay profile (APDP) for each WSS region of 10 wavelengths [17] can be calculated as follows:

$$
P_{h}\left(t_{k}, \tau\right)=\frac{1}{\operatorname{Num}} \sum_{n=0}^{\text {Num-1 }} P\left(t_{k}+n \Delta t, \tau\right) .
$$

In (2), we obtain the APDP in time of $t_{k}$ by averaging the $n$ instantaneous PDPs of $P(t, \tau)$ from time in $t_{k}$ to $t_{k}+n \Delta t$. $t_{k}$ is the first moment of each WSS window, and $t_{k}=\{0$, Num $\Delta t$ $, \ldots, \mathrm{Nt} \Delta t-\mathrm{Num} \Delta t\}$; Nt is the total chirp number in the test process. We chose the fastest speed of the two test cars during the measurement to get the integer number of chirps Num in each 10 -wavelength window $(0.508 \mathrm{~m})$ [17]. $\Delta t$ is the chirp interval of $517.2 \mu \mathrm{s}$. 


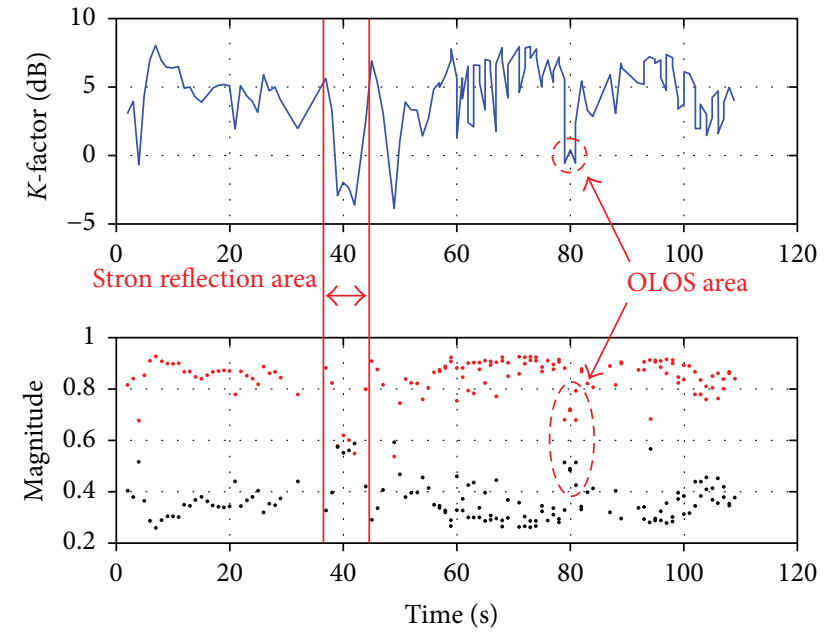

- Parameter $\rho$

- Parameter $\sigma$

(a)

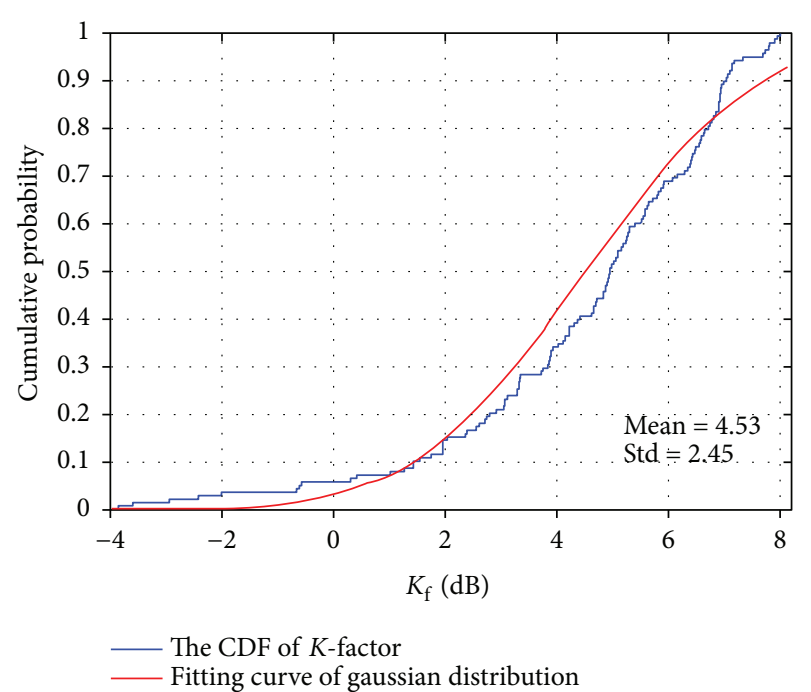

(b)

Figure 5: (a) $K$-factor estimation result; (b) CDF of the $K$-factors.

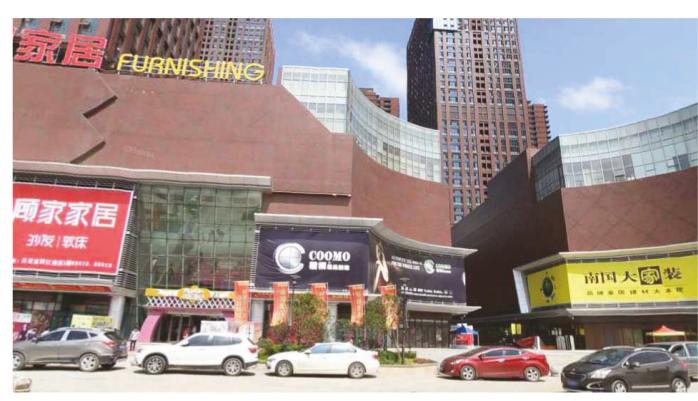

Figure 6: Street building appearing at $40 \mathrm{~s}$.

Figure 7 depicts the LOS path in red. It approximately parallels the time axis, indicating that the distance between the two cars does not change much during the measurement process. A significant reflection path (reflection path 1) separate from the LOS path appears from $10 \mathrm{~s}$ to $50 \mathrm{~s}$ with an excess delay of $150 \mathrm{~ns}$, as shown in Figure 7. According to satellite images (Google Earth) and our measurement videos, there is a large building on the street (Figure 6) near the TX and RX (about $33 \mathrm{~m}$ away from the road). Considering the average TX-RX distance (around $14 \mathrm{~m}$ ), the APDP in Figure 8, and the geometric diagram shown in Figure 9, we can determine that the reflection path 1 in Figure 7 is caused by a reflection on the surface of this building. Similarly, reflection path 2 (from $50 \mathrm{~s}$ to $100 \mathrm{~s}$ ) and reflection path 3 (occurring after $100 \mathrm{~s}$ ) are also derived from different buildings on the sides of the street. Therefore, reflections caused by street buildings are common phenomena in dense urban areas.

As shown in Figure 7, the magnitude of reflection path 1 suddenly increases from $-60 \mathrm{~dB}$ to $-42 \mathrm{~dB} \sim-35 \mathrm{~dB}$ around $40 \mathrm{~s}$, forming a strong reflection path. According to our data, part of the building surface is smooth (e.g., large panes of glass and marble), which contributes to the large energy of the reflection path, which is almost as high as that of the LOS path in Figure 8. Therefore, in dense urban areas, the smooth surfaces of street buildings will cause strong reflections. Its influence on the signal channel path loss parameters, both delay and Doppler spreads, is discussed below.

In addition to the reflection phenomena derived from the buildings rising above the street, we can also observe many other reflection paths (Figure 7) moving up or down from the LOS path over time. They are mainly caused by pedestrian bridges, traffic signs, and some other facilities next to the road. In summary, the large number of reflections in this dense urban area indicates that the multipath effect is very obvious in this scenario.

According to radio transmission theory, path loss is influenced by the radiation of the transmitter and the characteristics of the propagation channel such as reflection, diffraction, and shadowing $[34,35]$. The path loss is calculated by

$$
P_{\mathrm{LS}}=P_{\mathrm{TX}}+G_{\mathrm{TX}}+G_{\mathrm{RX}}-P_{\mathrm{RX}} .
$$

In (3), $P_{\mathrm{LS}}$ is the path loss, $P_{\mathrm{TX}}$ is the TX power, $G_{\mathrm{TX}}$ is the transmit antenna gain, $G_{\mathrm{RX}}$ is the receiving antenna gain, and $P_{\mathrm{RX}}$ is the RX received power.

In Figure 10 and Table 2, we compare how well the oneslope model, free space model, REL model, WINNER II-B1 model, WINNER II-C2 model, ITU-R P.1411 models (upper bound, lower bound, and average value), and the model in [36] match the measured data. Generally, the measured data and propagation path loss models vary with respect to the distance between the TX and RX; however, in this study, the distance between the two measurement cars did not vary much. To better observe the effect of strong reflection on the path loss of the signal at $42 \mathrm{~s}$, we treated time as the $x$-axis. At the same time, the degree of match for different areas of the 


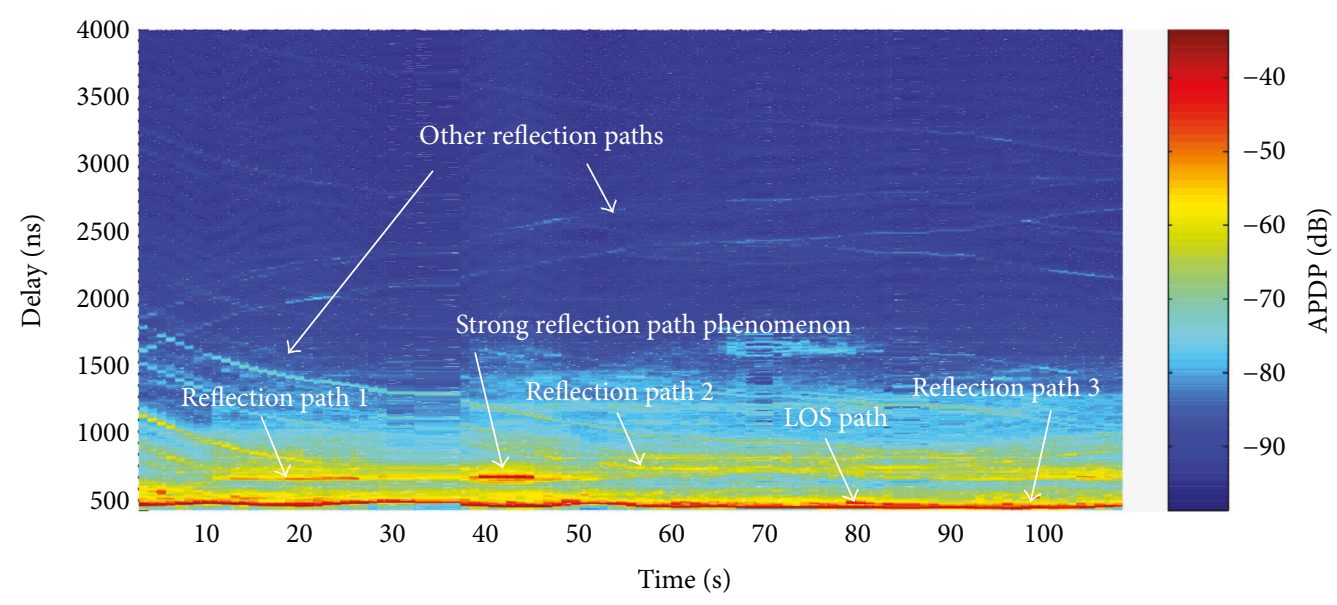

FIGURE 7: PDPs of the whole measurement.

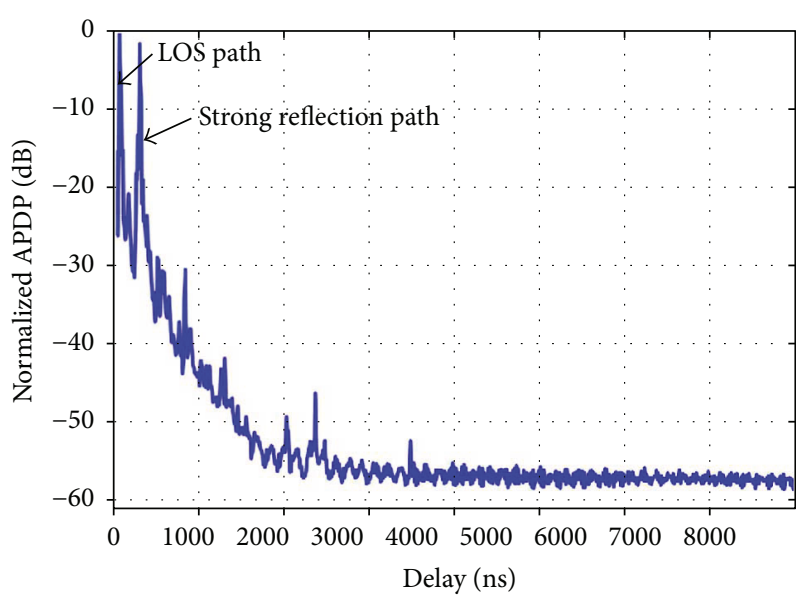

Figure 8: APDP at $42 \mathrm{~s}$.

test can also be observed. Of these models, only the ITU-R P.1411 (upper bound) model and the model in [36] are close to our data. The other seven models differ greatly from the measured data in Figure 10.

To select the optimal model in a quantitative way, we used three algorithms to compare the estimated data of the path loss models and the measured results of the study. The

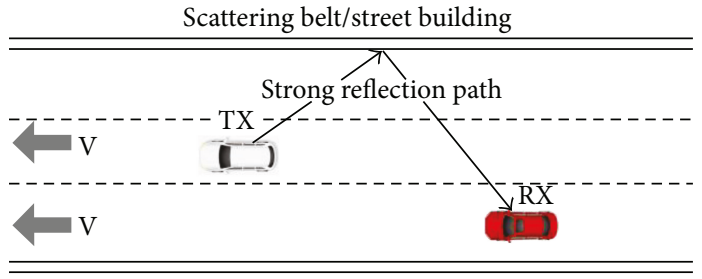

FIGURE 9: Schematic diagram of the reflection of the street buildings.

RMS error (RMSE); grey relational grade and mean absolute percentage error (GRG-MAPE), which is based on grey system theory; and the Pearson correlation coefficient and mean absolute percentage error (PCC-MAPE) were used to select the path loss model that best matches the measured data $[34,35]$. The algorithms are, respectively, expressed by the following formulas:

(a) RMSE:

$$
\rho_{\mathrm{RMSE}}=\sqrt{\frac{1}{n} \sum_{m=1}^{n}\left(h_{i}(m)-h_{0}(m)\right)^{2}} .
$$

(b) GRG-MAPE:

$$
\begin{aligned}
g\left(h_{0}(m), h_{i}(m)\right) & =\frac{\min _{i} \min _{m}\left|h_{0}(m)-h_{i}(m)\right|+\xi \cdot \max _{i} \max _{m}\left|h_{0}(m)-h_{i}(m)\right|}{\left|h_{0}(m)-h_{i}(m)\right|+\xi \cdot \max _{i} \max _{m}\left|h_{0}(m)-h_{i}(m)\right|}, \\
\rho_{\mathrm{GRG}} & =\frac{1}{n} \sum_{m=1}^{n} g\left(h_{0}(m), h_{i}(m)\right), \\
\rho_{\mathrm{MAPE}} & =1-\frac{1}{n} \sum_{m=1}^{n} \frac{\left|g\left(h_{0}(m), h_{i}(m)\right)\right|}{h_{0}(m)}, \\
\rho_{\mathrm{GRG}-\mathrm{MAPE}} & =\left|\alpha \cdot \rho_{\mathrm{GRG}}+\beta \cdot \rho_{\mathrm{MAPE}}\right| .
\end{aligned}
$$




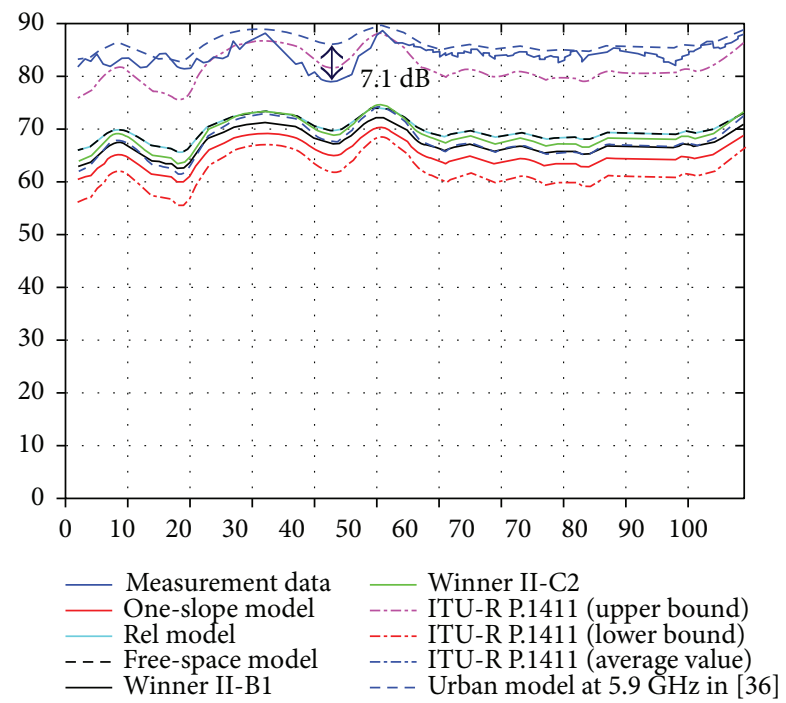

Figure 10: Measured data and propagation path loss models.

TABLe 2: Model comparison.

\begin{tabular}{lccc}
\hline Model type & RMSE & $\begin{array}{c}\text { GRG- } \\
\text { MAPE }\end{array}$ & $\begin{array}{c}\text { PCC- } \\
\text { MAPE }\end{array}$ \\
\hline One-slope model & 19.4059 & 0.7652 & 0.7387 \\
REL & 14.6283 & 0.8210 & 0.7899 \\
Free space model & 14.6277 & 0.8210 & 0.7900 \\
WINNER II-B1 & 17.1232 & 0.7916 & 0.7632 \\
WINNER II-C2 & 15.5849 & 0.8064 & 0.7800 \\
ITU-R P.1411 (upper bound) & 3.5962 & 0.9371 & 0.9102 \\
ITU-R P.1411 (lower bound) & 22.8422 & 0.7238 & 0.7020 \\
ITU-R P.1411 (average value) & 16.8854 & 0.7899 & 0.7663 \\
Urban model at 5.9 GHz in & 2.5339 & 0.9590 & 0.9242 \\
[36] & & & \\
\hline
\end{tabular}

(c) PCC-MAPE:

$$
\rho_{\mathrm{PCC}-\mathrm{MAPE}}=\left|\gamma \cdot \rho_{\mathrm{PCC}}+\kappa \cdot \rho_{\mathrm{MAPE}}\right| .
$$

Here, $h_{i}$ is the value predicted by one path loss model in Figure 10 and $h_{0}$ denotes measured data. Moreover, $n$ is the total number of all data. In (4), the RMSE takes into account the differences of the predicted and measured data. In (5), $g\left(h_{0}(m), h_{i}(m)\right)$ denotes the grey correlation coefficient of $h_{0}(m)$ and $h_{i}(m), \xi \in[0,1] \rho_{\mathrm{GRG}}$, where in general, $\xi=0.5$ [37]. In (6) and (8), $\rho_{\mathrm{GRG}}$ is the grey relational grade, and in (7), $\rho_{\mathrm{MAPE}}$ is calculated. Parameters $\rho_{\mathrm{PCC}}$ and $\rho_{\mathrm{MAPE}}$ in (9) are the grey relational coefficients of the grey system theory. Finally, $\alpha, \beta, \gamma$, and $\kappa$ are the weights, where $\alpha+\beta=\gamma+\kappa=1$. In this study, $\alpha=\gamma=0.1$ and $\beta=\kappa=0.9$ are suitable settings based on the observed data $[34,35]$.

Smaller RMSE values and bigger GRG-MAPE and PCCMAPE values represent better matches. The results of the dense city traffic congestion scenario in Table 2 shows that the path loss model of the urban environment at $5.9 \mathrm{GHz}$ in [36] (RMSE: 2.5339, GRG-MAPE: 0.9590, and PCC-MAPE: 0.9242 ) is the optimal model. For path loss, the results of this study are consistent with those of [36].

Note that the urban model at $5.9 \mathrm{GHz}$ in [36] matches well with all measured data except at the strong reflection at $40 \mathrm{~s}$. At $42 \mathrm{~s}$, when the reflection path is the strongest, the difference between the measured data and model in [36] is $7.1 \mathrm{~dB}$. The large gap in this section indicates that the reflection path has a large effect in the power domain on the $5.9 \mathrm{GHz}$ signal in urban areas.

\subsection{Delay Spread and Doppler Spread}

3.3.1. Delay Spread. The delay spread is a statistical description of the delay characteristics for radio channels. It reflects the multipath effect, which is closely related to environmental factors [38]. Many experimental results show that the RMS delay spread has a direct impact on the error floor caused by the delay dispersion $[6,18,36,39,40]$.

Mean delay spread $\tau_{\mathrm{m}}$ (shown in (10)) is defined as the normalized first-order moment of the power delay profile, while the RMS delay spread $\tau_{\text {rms }}$ (shown in (11)) is the normalized second-order central moment [32]. Using (2), they can be calculated as follows:

(a) Mean delay spread:

$$
\tau_{\mathrm{m}}=\frac{\int_{-\infty}^{\infty} P_{h}(t, \tau) \tau d \tau}{P_{m}}
$$

(b) RMS delay spread:

$$
\tau_{\mathrm{rms}}=\sqrt{\frac{\int_{-\infty}^{\infty} P_{h}(t, \tau) \tau^{2} d \tau}{P_{m}}-\tau_{\mathrm{m}}^{2}} .
$$

where $P_{m}$ is the zero-order moment and a reflection path is defined to be $6 \mathrm{~dB}$ higher than the noise floor.

Many papers have measured the RMS delay spread for different scenarios. The authors of $[30,39]$ pointed out that the RMS delay spread of the V2V expressway in rural and urban environments is $50 \mathrm{~ns}$. In [18], it was found that in crossroads and tunnels, the RMS delay spread of a nonLOS (NLOS) path was 130 ns larger than that of a LOS path in the same scenario. Moreover, [6] measured the average RMS delay spread for a LOS path as $59 \mathrm{~ns}$, whereas the RMS delay spread for the NLOS path, which was due to a large bus interrupting the path, could reach $500 \mathrm{~ns}$. In this study, Section 3.1 indicates that a LOS path is the dominant component affecting our data in certain parts of the dense urban area. The RMS delay spread, as a function of time, is depicted in Figure 11. We observe that the values of the RMS delay spread stay between $60 \mathrm{~ns}$ and $100 \mathrm{~ns}$ most of the time. The RMS delay spread we measured in this study was larger than the values in [39-41] in the urban environment and urban LOS scenarios. Note that the RMS delay spread reached a maximum of $120 \mathrm{~ns}$ around $40 \mathrm{~s}$, which coincides with regions where a strong reflection path appears. 


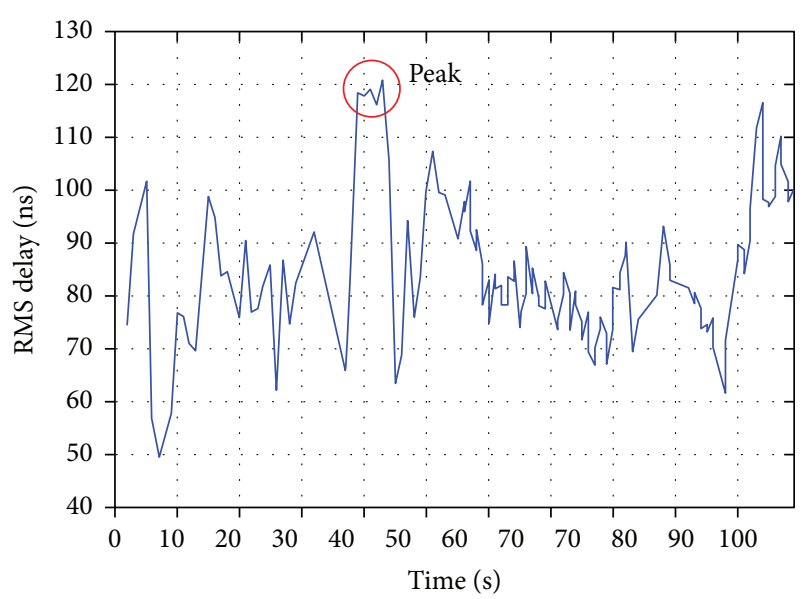

FIgURE 11: RMS delay spread as a function of time.

TABle 3: Delay comparison.

\begin{tabular}{lc}
\hline RMS delay spread of $1-36 \mathrm{~s}$ & $\mathrm{~ns}$ \\
$10 \%$ & 56.68 \\
$50 \%$ & 79.77 \\
$90 \%$ & 96.78 \\
Fitting distribution of $1-36 \mathrm{~s}$ & $\mathrm{n} / \mathcal{N}(4.35207,0.186456)$ \\
RMS delay spread of $37-45 \mathrm{~s}$ & 63.16 \\
$10 \%$ & 116.1 \\
$50 \%$ & 120.7 \\
$90 \%$ & $\mathrm{~W}(109.865,6.14114)^{*}$ \\
Fitting distribution of $37-45 \mathrm{~s}$ & 71.36 \\
RMS delay spread of $46-109 \mathrm{~s}$ & 81.46 \\
$10 \%$ & 100.2 \\
$50 \%$ & $\ln \mathcal{N}(4.42269,0.134396)$ \\
$90 \%$ & \\
Fitting distribution of $46-109 \mathrm{~s}$ & \\
\hline $\mathscr{W}(\alpha, \beta)$ represents the Weibull distribution $(\alpha$ is the scale parameter, and $\beta$ \\
is the shape parameter).
\end{tabular}

To investigate the effects of a strong reflection path, we divided the measurement route into three parts: part 1 was $1-36 \mathrm{~s}$, part 2 was $37-45 \mathrm{~s}$, and part 3 was $46 \mathrm{~s}-109 \mathrm{~s}$ in Tables 3 and 4 . The strong reflection path appears during part 2.

According to Table 3, the values of $\tau_{\mathrm{rms}}$ in part 2 are larger than those of parts 1 and 3. Because the number of paths (about 40) in part 2 are similar to those in part 1 , increasing the values of $\tau_{\mathrm{rms}}$ in part 2 is caused by a strong reflection path. Therefore, strong reflection paths can increase the RMS delay spread. This is because the strong reflection path leads to a greater fluctuation of APDP around $40 \mathrm{~s}$. Moreover, according to the AIC results, the best-fit distribution of part 2 is the Weibull distribution, which is different from the other two parts. The changes in the statistical properties of the delay are caused by the strong path (Figure 7) caused by the powerful reflection on the surface of the building in Figure 6 .
TABle 4: Doppler comparison.

\begin{tabular}{lc}
\hline RMS Doppler spread of 1-36s & $\mathrm{Hz}$ \\
$10 \%$ & 41.07 \\
$50 \%$ & 44.2 \\
$90 \%$ & 51.05 \\
Fitting distribution of 1-36s & $\ln \mathcal{N}(3.81201,0.0893328)$ \\
RMS Doppler spread of 37-45 s & $\mathrm{Hz}$ \\
$10 \%$ & 44.33 \\
$50 \%$ & 50.33 \\
$90 \%$ & 53.59 \\
Fitting distribution of 37-45 s & $\mathscr{W}(50.7048,24.7391)^{*}$ \\
RMS Doppler spread of $46-109 \mathrm{~s}$ & $\mathrm{~Hz}$ \\
$10 \%$ & 41.76 \\
$50 \%$ & 47.36 \\
$90 \%$ & 61.58 \\
Fitting distribution of $46-109 \mathrm{~s}$ & $\ln \mathcal{N}(3.92324,0.143616)$
\end{tabular}

* $\mathscr{W}(\alpha, \beta)$ represents the Weibull distribution ( $\alpha$ is the scale parameter, and $\beta$ is the shape parameter).

The CDFs of the mean and RMS delays are shown in Figure 12, where $90 \%$ of the mean delay shift ranges from $50 \mathrm{~ns}$ to $100 \mathrm{~ns}$. The RMS delay spread, which follows a lognormal distribution, is within the range $\ln \mathcal{N}$ (4.41877, 0.16416).

This result shows that the RMS delay spread for a traffic jam scenario in Chinese dense urban areas is smaller than the results in [40] for the urban LOS environment (RMS delay of 157.5-286.6ns) but larger than the rural LOS RMS delay (21.6 ns) near Detroit, Michigan, at $5.9 \mathrm{GHz}$. In paper [41] at $5.12 \mathrm{GHz}$ in American cities, the result is larger than open-area low traffic density areas (mean RMS delay of $53.2 \mathrm{~ns}$ ) but smaller than the RMS delay of the rest of the environment (mean RMS delays of 125.8-236 ns).

3.3.2. Doppler Spread. Both delay and Doppler spreads are very useful statistical characteristics of the V2V channel [42].

$$
\begin{aligned}
P_{B m} & =\int_{-\infty}^{\infty} P_{B}(v) d v, \\
v_{m} & =\frac{\int_{-\infty}^{\infty} P_{B}(v) v d v}{P_{B m}}, \\
S_{v} & =\sqrt{\frac{\int_{-\infty}^{\infty} P_{B}(v) v^{2} d v}{P_{B m}}-v_{m}^{2}} .
\end{aligned}
$$

In (12), (13), and (14), $P_{B}$ denotes the scattering function [23], $v_{m}$ is the mean Doppler shift, and $S_{v}$ is the RMS Doppler spread.

The authors of [18] tested many scenarios and found that the results of the RMS Doppler spread were small if two test cars had a small relative speed. This is similar to the scenario of a car following another in this study. 


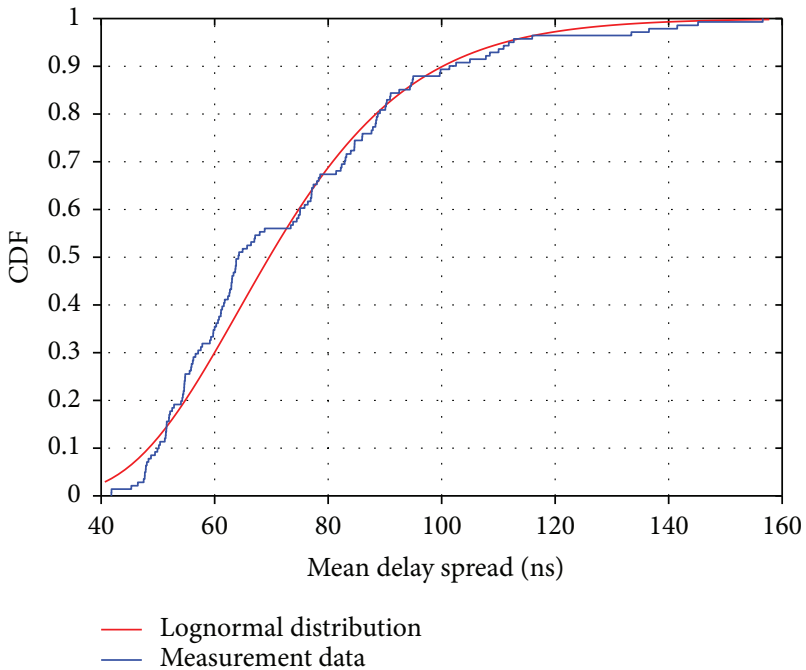

(a)

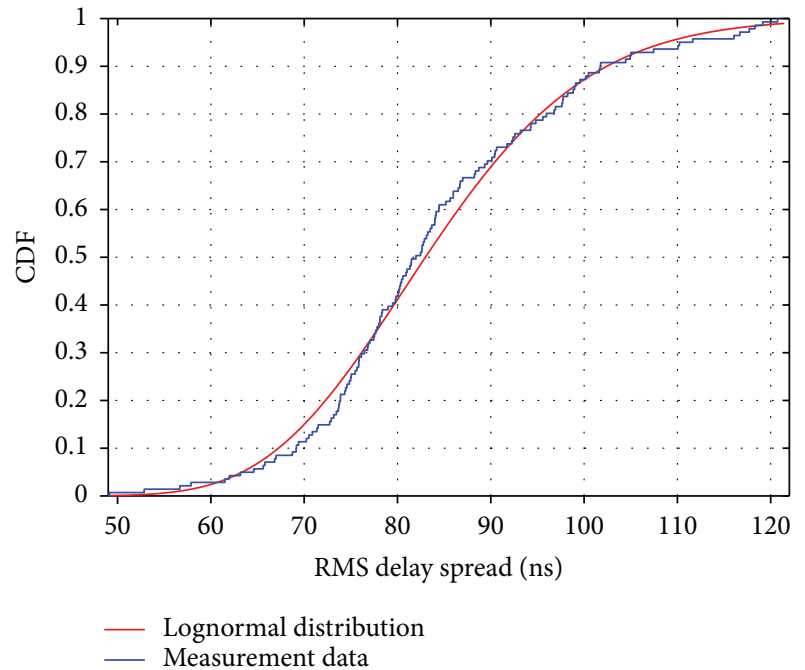

(b)

Figure 12: Delay spread: (a) CDF of the mean delay shift and (b) CDF of the RMS delay spread.

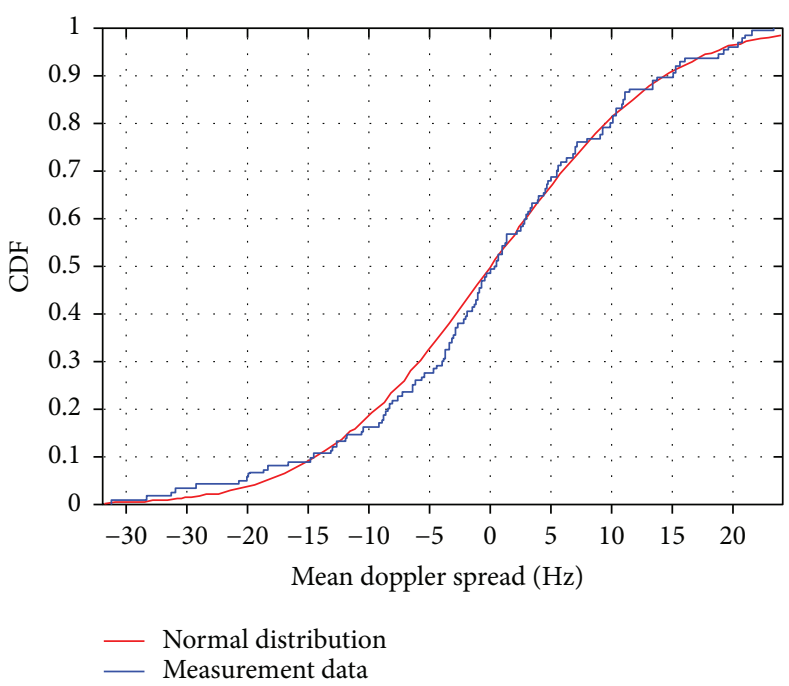

(a)

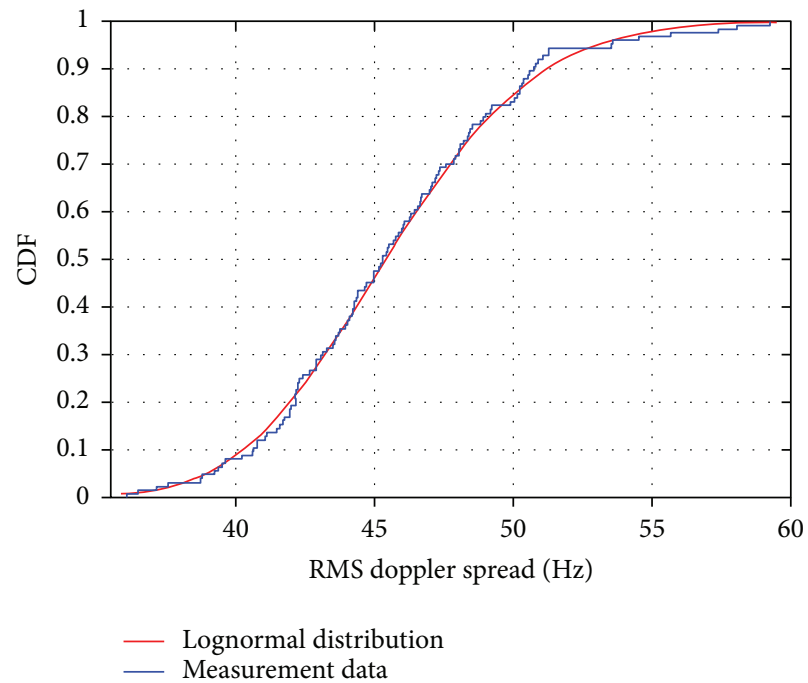

(b)

FIGURE 13: Doppler spread: (a) CDF of the mean Doppler shift and (b) CDF of the RMS Doppler spread.

For the overall traffic jam scenario in a dense urban region, the CDF of the Doppler values can be found in Figure 13, which indicate that they tend to follow a lognormal distribution.

In contrast to [18], we divided the measurement route into the three parts used for the delay spread analysis to study the impact of the strong reflection on the RMS Doppler spread in Table 4 . The values of $S_{v}$ for all three parts are similar. This is because of the similar speeds and numbers of paths (around 40 reflection paths) for all parts. Although the values of the three parts are similar, the best-fitting distribution for part 2 is the Weibull distribution, and that for parts 1 and 3 is the lognormal distribution. This result is also because of the impact of the strong reflection caused by the street building.
The values for delay and Doppler spread under different conditions over the whole section $(10 \%, 50 \%$, and $90 \%)$ are summarized in Table 5.

3.4. U-Shape Delay-Doppler Spectrum. The delay-Doppler spectrum is a very useful tool in frequency domain analysis $[19,20]$. We obtained the delay-Doppler spectrum using a fast Fourier transform (FFT) over the same quasi-stationary window of 10 wavelengths. Here, $P_{B}(v, \gamma)$ is acquired by (15) [23], where $\Delta \gamma$ represents the Doppler resolution for $s=-258.3,-258,-257.7, \ldots, 0, \ldots, 258.3$, and is $3.94 \mathrm{~Hz}$.

$$
\begin{aligned}
P_{B}(v, \gamma) & =\left.|\mathrm{FFT}| h(t, \tau)\right|^{2}, \quad v=s \cdot \Delta \gamma, \\
f_{d} & =\frac{v}{\lambda} \cos \theta_{1} .
\end{aligned}
$$


TABLE 5: Channel estimation results for dense city congestion scenario.

\begin{tabular}{lcc}
\hline Measurement items & \multicolumn{2}{c}{ Value } \\
\hline Best-fit distribution & Ricean distribution \\
& Ricean & $97.87 \%$ \\
& Nakagami-m & $1.42 \%$ \\
AIC results & Weibull & $0.71 \%$ \\
& Lognormal & $0.00 \%$ \\
& Rayleigh & $0.00 \%$ \\
Mean delay shift of the full section & {$[$ Nanosecond] } \\
$10 \%$ & 50.16 \\
$50 \%$ & 64.18 \\
$90 \%$ & 101.4 \\
RMS delay spread of the full section & {$[\mathrm{ns}]$} \\
$10 \%$ & 69.17 \\
$50 \%$ & 81.98 \\
$90 \%$ & 101.7 \\
Fitting distribution & $\ln (4.41877$, \\
Mean Doppler of the full section & $0.16416)$ \\
$10 \%$ & {$[\mathrm{~Hz}]$} \\
$50 \%$ & -16.6 \\
$90 \%$ & -1.413 \\
RMS Doppler spread of the full section & 13.65 \\
$50 \%$ & {$[\mathrm{~Hz}]$} \\
$90 \%$ & 40.39 \\
Fitting distribution & 46.12 \\
Max TX-RX distance & 52.09 \\
\hline & $0.0941553)$ \\
& $-0.176 \mathrm{~km} / \mathrm{h}$ \\
& $20.4 \mathrm{~m}$ \\
\hline
\end{tabular}

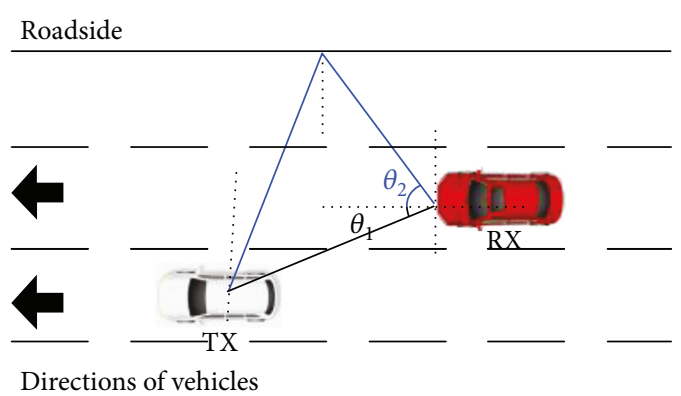

FIgURE 14: Doppler effect diagram.

In (16), $f_{d}$ is the Doppler frequency shift in $\mathrm{Hz}, v$ is the TX and RX relative velocity, $\lambda$ is the wavelength, and $\theta_{1}$ is the angle (units: degree) shown in Figure 14.

Figure 15 is a screenshot of the experiment's video at $20 \mathrm{~s}$, and Figure 16 is the delay-Doppler spectrum for $20 \mathrm{~s}$. Because of the short distance between the two cars, the delay of the LOS path is very small (the point marked by the white arrow in Figure 16 is the LOS path). The measured GPS data show that when TX moves away from RX, this corresponds to a

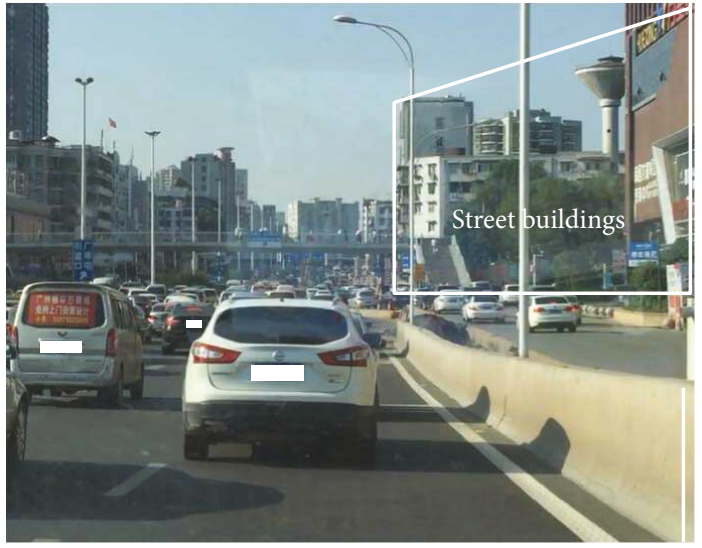

Figure 15: Screenshot of the experimental video at $20 \mathrm{~s}$.

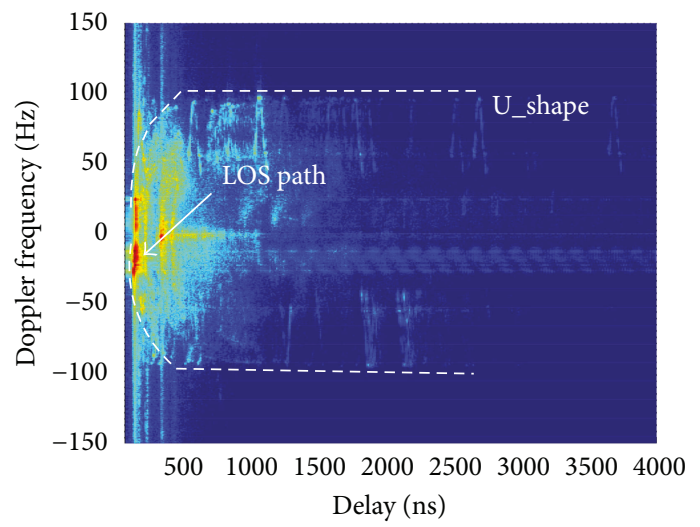

FIgURE 16: Delay-Doppler spectrum at $20 \mathrm{~s}$; this figure is a locally enlarged image, where the $x$-axis range is $1-4000$ ns and the $y$-axis range is -150 to $150 \mathrm{~Hz}$.

negative Doppler shift of the LOS path. In the delay-Doppler spectrum, a U-shape was formed from 50 to $2800 \mathrm{~ns}$. Similar U-shape phenomena were found in [43] for $5.2 \mathrm{GHz}$ on a forested road somewhere near Munich as well as in [44], which studied aeronautical channels. Walter et al. used the ellipse method to analyze this phenomenon and modeled it in [45]. Moreover, [45] defined a U-shaped delay-Doppler spectrum as a peculiar phenomenon of scatter channels. Using Walter's theory, our measurement environment is equivalent to the geometric model shown in Figure 17. This proves that $\mathrm{V} 2 \mathrm{~V}$ in dense urban areas at low speeds also consists of scatter channels. Compared with Walter's forested road and aeronautical channels, V2V channels are more commonly found in the scenario in this study. Scatter channels formed in urban city areas also have unique characteristics.

The explanation for the results in Figure 17 is as follows. The TX and RX vehicles travelled in the same direction in the congested traffic, and their small relative velocities and short TX-RX distance caused a small Doppler frequency shift and delay values, which was analyzed in Section 3.3. Consequently, LOS path $a$ in Figure 17 forms point $a$ in Figure 18. The $b_{M}(M=1,2,3, \ldots, m), c$, and $d_{N}(N=1,2,3, \ldots, n)$ paths are the reflection paths derived from the surface of the building in Figure 17. Here, $M$ denotes the number of scatter 


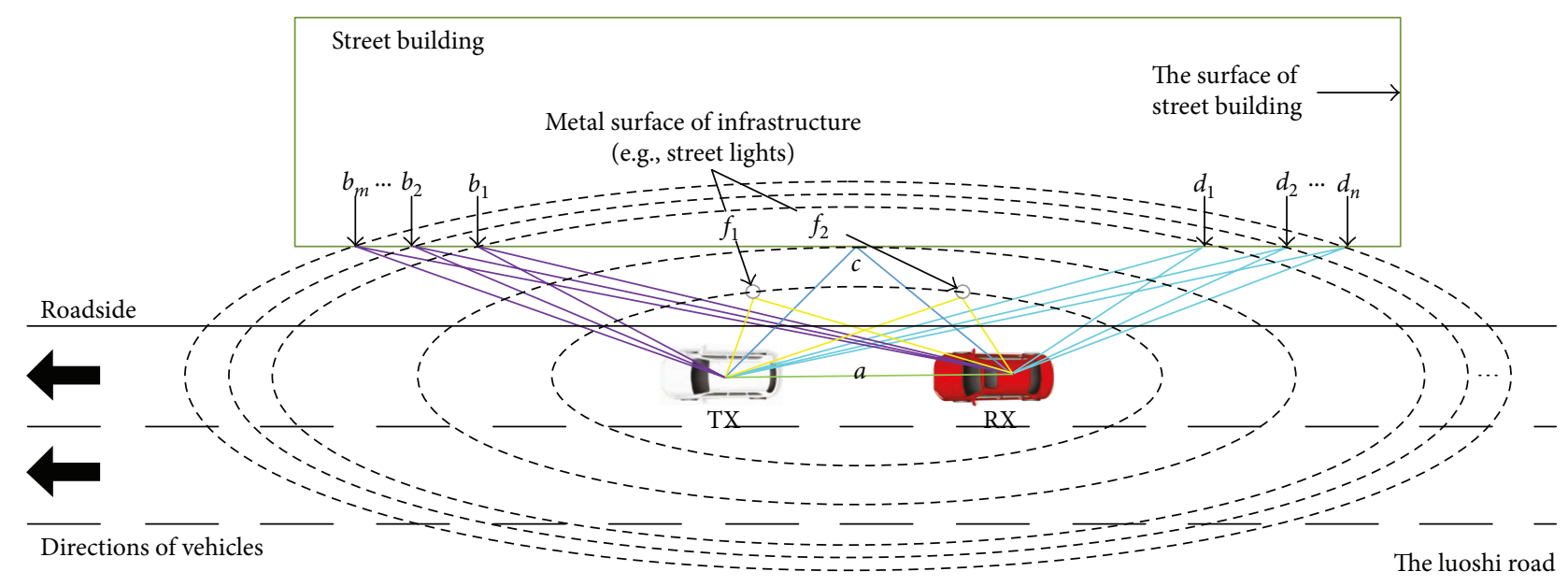

Figure 17: Scatterer distribution.

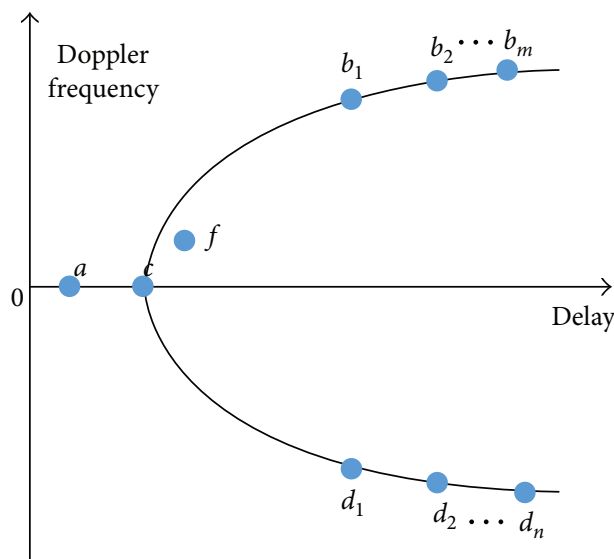

Figure 18: Delay-Doppler spectrum of points $a-d$ and $f$.

points in front of the RX. We assume this part of the radio signals are reflected to the RX from scatter points $b_{1}, b_{2}, \ldots, b_{m}$. From $b_{1}$ to $b_{m}$, a larger transmission distance will lead to a bigger access delay and a smaller incidence angle $\theta_{2}$ (as shown in Figure 14), which leads to a higher Doppler frequency shift. Thus, points $b_{M}$ form the upper arm of the U-shape delayDoppler spectrum in Figure 18. Compared with points $b_{M}$, points $d_{N}$ contribute to the opposite process. TX and RX are moving far away from these points, and this causes the negative Doppler shift values in Figure 18.

Point $c$ is located between TX and RX. Therefore, the access of point $c$ in Figure 18 is smaller than those of points $b_{M}$ and $d_{N}$. Meanwhile, TX is moving further from scattering point $c$ (Figure 17) and RX is approaching it. This phenomenon causes the Doppler of point $c$ to be a very small value or equal to zero. We can also investigate the strong reflectors around $40 \mathrm{~s}$ in the frequency domain. Figure 19 shows the delay-Doppler spectrum at $42 \mathrm{~s}$. The highlight of the strong reflection path at $150 \mathrm{~ns}$ can be regarded as position $c$ in Figure 18, which means the reflector is in the middle of two vehicles. This result supports our inference in Sections 3.1 and 3.2 that a building causes the powerful reflection around

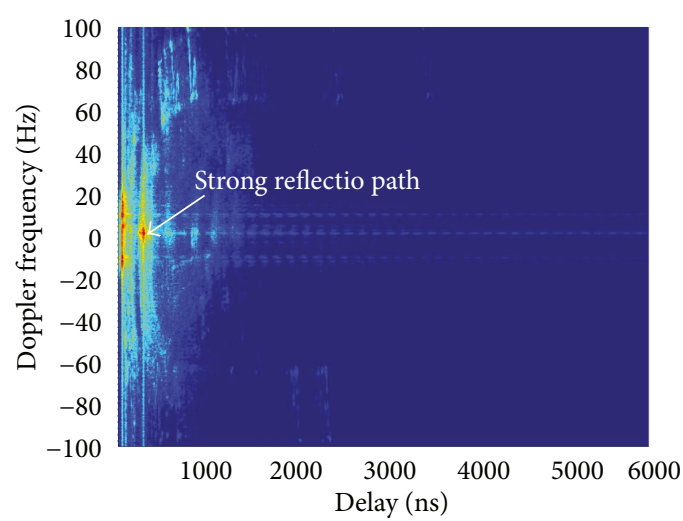

Figure 19: Delay-Doppler spectrum at $42 \mathrm{~s}$; this figure is a locally enlarged image, where the $x$-axis is $1-6000 \mathrm{~ns}$ and the $y$-axis is -100 to $100 \mathrm{~Hz}$.

40 s. Moreover, some metal infrastructure on the roadside (e.g., $f_{1}$ and $f_{2}$ in Figure 17) may also have caused other reflection phenomena. The corresponding points appear between the upper and lower arms of the U-shape in Figure 18. The measurement-based delay-Doppler spectrum at $20 \mathrm{~s}$ (Figure 16) proves our assumption above. However, it is different from the theoretical conditions. The surfaces of the street buildings are not a uniform texture. This causes strong and weak points with different delays in the U-shaped delayDoppler spectrum. In summary, a dense urban environment with roadside buildings will also cause a U-shape to occur in the delay-Doppler spectrum, similar to that of a forest road or aeronautical channels. This can hence be determined to be a scattering channel.

The measurement results of the entire section are summarized in Table 5.

\section{Conclusion}

In this study, we performed an experiment for a $\mathrm{V} 2 \mathrm{~V}$ scenario at $5.9 \mathrm{GHz}$ in an urban congestion environment in Wuhan, China. The main aim of this test was to measure 
the signal transmission of two cars close to each other and travelling at low speeds in heavy traffic with dense street buildings along the street.

In this paper, small-scale amplitude fading and the $K$ factor were first analyzed. A 10-wavelength sliding window and the AIC algorithm were used to determine the amplitude-fading distribution. The fitting degree is $97.87 \%$ to the Ricean distribution, and the $K$-factor is positive most of the time which indicates that LOS path energy is dominant most of the time in the measurement of this paper. The reduction of the $K$-factor at $40 \mathrm{~s}$ and $80 \mathrm{~s}$ is due to a strong reflection caused by a building, and the OLOS channel is caused by other cars.

An analysis of the PDPs showed that in the scenario in this study, the buildings have a significant effect on the signal by reflecting it. This forms strong reflection paths parallel to the $x$-axis in the PDP figure. For the large-scale fading, we tried a number of path loss models to match the measured data, and the RMSE, GRG-MAPE, and PCC-MAPE metrics were used to determine the best matching models. The path loss model of an urban area at $5.9 \mathrm{GHz}$ in [36] (RMSE: 2.5339, GRG-MAPE: 0.9590, and PCC-MAPE: 0.9242) is the optimal model. However, in the strong reflection region at about $40 \mathrm{~s}$, a large deviation of about $7.1 \mathrm{~dB}$ occurs between the model in [36] and the measured data. This shows that a strong reflection path has a substantial affect in the power domain of the signal.

We then conducted a statistical study of the channel characteristics. Mean delay shift (10\%-90\%: 50.16-101.4 ns) and RMS delay spread (10\%-90\%: 69.17-101.7 ns) all follow a lognormal distribution, and this proves that the scenario of this study has typical urban statistical features. Because the relative speed of the two cars was very small, the values of the Doppler spread are also small; mean Doppler shift (10\%-90\%: -16.6 to $13.65 \mathrm{~Hz}$ ) and RMS Doppler spread (10\%-90\%: 40.39-52.09 Hz) also satisfy the lognormal distribution. At the same time, to study the effect of a strong reflection path, we divided the experimental data into three parts. We found that the strong reflection path in part 2 can cause the RMS delay spread to increase and the best-fit distributions for the RMS delay spread and RMS Doppler spread to change from a lognormal distribution in parts 1 and 3 to a Weibull distribution.

The delay-Doppler spectrum was also analyzed, and the characteristics of a scattering channel were found in this scenario. A clear U-shape can be seen in the delay-Doppler spectrum. It is caused by the guardrail and other structures on the roadside in dense cities. The different textures of building surfaces lead to the nonuniform upper and lower arms of the U-shape.

To summarize, this study presents the impact of congestion on V2V channel characteristics, which will be helpful in the design of vehicle networking systems in the future.

\section{Conflicts of Interest}

The authors declare that there is no conflict of interest regarding the publication of this paper.

\section{Acknowledgments}

This study has been performed through the Project of Young Scientists Fund of National Natural Science Foundation of China (no. 61701356). The authors thank Super Radio AS and Ningbo Allmeasech Co. Ltd., who generously supplied the measurement equipment. With their support, the authors completed the measurements and other research. The authors also appreciate the support and help of their other friends and colleagues in their research group during the measurement experiments.

\section{References}

[1] P. Papadimitratos, D. L. F. Arnaud, K. Evenssen, R. Brignolo, and S. Cosenza, "Vehicular communication systems: enabling technologies, applications, and future outlook on intelligent transportation," IEEE Communications Magazine, vol. 47, no. 11, pp. 84-95, 2009.

[2] H. Schumacher, H. Tchouankem, J. Nuckelt et al., "Vehicle-tovehicle IEEE $802.11 \mathrm{p}$ performance measurements at urban intersections," in 2012 IEEE International Conference on Communications (ICC), pp. 7131-7135, Ottawa, ON, Canada, 2012.

[3] FCC, "Federal Communications Commission news," 1999, https://transition.fcc.gov/Bureaus/Engineering_Technology/ News_Releases/1999/nret9006.html.

[4] P. Liu, B. Ai, D. Matolak, R. Sun, and Y. Li, "5-GHz vehicle-tovehicle channel characterization for example overpass channels," IEEE Transactions on Vehicular Technology, vol. 65, no. 8, pp. 5862-5873, 2016.

[5] R. Sun, D. W. Matolak, and P. Liu, "5-GHz V2V channel characteristics for parking garages," IEEE Transactions on Vehicular Technology, vol. 66, p. 1, 2016.

[6] R. He, A. F. Molisch, F. Tufvesson, Z. Zhong, B. Ai, and T. Zhang, "Vehicle-to-vehicle propagation models with large vehicle obstructions," IEEE Transactions on Intelligent Transportation Systems, vol. 15, no. 5, pp. 2237-2248, 2014.

[7] L. Bernado, A. Roma, A. Paier et al., "In-tunnel vehicular radio channel characterization," in IEEE 73rd Vehicular Technology Conference (VTC Spring), pp. 1-5, Yokohama, Japan, 2011.

[8] A. Paier, J. Karedal, N. Czink et al., "First results from car-tocar and car-to-infrastructure radio channel measurements at 5.2GHZ," in 2007 IEEE 18th International Symposium on Personal, Indoor and Mobile Radio Communications, pp. 1-5, Athens, Greece, 2007.

[9] T. Abbas, L. Bernado, A. Thiel, C. F. Mecklenbrauker, and F. Tufvesson, "Measurements based channel characterization for vehicle-to-vehicle communications at merging lanes on highway," in 2013 IEEE 5th International Symposium on Wireless Vehicular Communications (WiVeC), pp. 1-5, Dresden, Germany, 2013.

[10] A. Paier, T. Zemen, L. Bernado et al., "Non-WSSUS vehicular channel characterization in highway and urban scenarios at $5.2 \mathrm{GHz}$ using the local scattering function," in 2008 International ITG Workshop on Smart Antennas, pp. 9-15, Vienna, Austria, 2008.

[11] P. Liu, D. W. Matolak, B. Ai, and R. Sun, "Path loss modeling for vehicle-to-vehicle communication on a slope," IEEE Transactions on Vehicular Technology, vol. 63, no. 6, pp. 2954-2958, 2014. 
[12] L. Bernado, T. Zemen, J. Karedal et al., "Multi-dimensional $\mathrm{K}$-factor analysis for V2V radio channels in open sub-urban street crossings," in 21st Annual IEEE International Symposium on Personal, Indoor and Mobile Radio Communications, pp. 58-63, Instanbul, Turkey, 2010.

[13] J. J. Park, M. D. Kim, and H. K. Chung, "Characteristics of Ricean K-factor in wideband indoor channels at $3.7 \mathrm{GHz}$," in 2010 4th International Conference on Signal Processing and Communication Systems, pp. 1-5, Gold Coast, QLD, Australia, 2010.

[14] C. Siriteanu, X. Shi, and Y. Miyanaga, "MIMO zero-forcing detection performance for correlated and estimated Rician fading with lognormal azimuth spread and K-factor," in 2011 IEEE International Conference on Communications (ICC), pp. 1-5, Kyoto, Japan, 2011.

[15] T. Zhou, C. Tao, L. Liu, and Z. Tan, "Ricean K-factor measurements and analysis for wideband radio channels in high-speed railway U-shape cutting scenarios," in 2014 IEEE 79th Vehicular Technology Conference (VTC Spring), pp. 1-5, Seoul, South Korea, 2014

[16] S. A. M. Tariq, C. Despins, S. Affes, and C. Nerguizian, "Experimental results of Rician $\mathrm{K}$-factor and co-polarization ratio of $60 \mathrm{GHz}$ wireless channel in an underground mine gallery," in 2015 IEEE International Conference on Ubiquitous Wireless Broadband (ICUWB), pp. 1-5, Montreal, QC, Canada, 2015.

[17] R. He, Z. Zhong, B. Ai, G. Wang, J. Ding, and A. F. Molisch, "Measurements and analysis of propagation channels in high-speed railway viaducts," IEEE Transactions on Wireless Communications, vol. 12, no. 2, pp. 794-805, 2011.

[18] L. Bernado, T. Zemen, F. Tufvesson, A. F. Molisch, and C. F. Mecklenbräuker, "Delay and Doppler spreads of nonstationary vehicular channels for safety-relevant scenarios," IEEE Transactions on Vehicular Technology, vol. 63, no. 1, pp. 82-93, 2013.

[19] A. F. Molisch, F. Tufvesson, J. Karedal, and C. Mecklenbrauker, "A survey on vehicle-to-vehicle propagation channels," IEEE Wireless Communications, vol. 16, no. 6, pp. 12-22, 2009.

[20] A. Paier, J. Karedal, N. Czink et al., "Car-to-car radio channel measurements at $5 \mathrm{GHz}$ : pathloss, power-delay profile, and delay-Doppler spectrum," in 2007 4th International Symposium on Wireless Communication Systems, pp. 224-228, Trondheim, Norway, 2007.

[21] L. Cheng, B. E. Henty, F. Bai, and D. D. Stancil, "Highway and rural propagation channel modeling for vehicle-to-vehicle communications at $5.9 \mathrm{GHz}$," in 2008 IEEE Antennas and Propagation Society International Symposium, pp. 1-4, San Diego, CA, USA, 2008.

[22] L. Bernado, T. Zemen, F. Tufvesson, A. F. Molisch, and C. F. Mecklenbräuker, "The (in-) validity of the WSSUS assumption in vehicular radio channels," in 2012 IEEE 23rd International Symposium on Personal, Indoor and Mobile Radio Communications - (PIMRC), pp. 1757-1762, Sydney, NSW, Australia, 2012.

[23] A. F. Molisch, Wireless Communications, John Wiley \& Sons, Hoboken, NJ, USA, 2007.

[24] U. G. Schuster, H. Bolcskei, and G. Durisi, "Ultrawideband channel modeling on the basis of information-theoretic criteria," IEEE Transactions on Wireless Communications, vol. 6, no. 7, pp. 2464-2475, 2005.

[25] S. Wyne, A. P. Singh, F. Tufvesson, and A. F. Molisch, "A statistical model for indoor office wireless sensor channels," IEEE Transactions on Wireless Communications, vol. 8, no. 8, pp. 4154-4164, 2009.
[26] X. H. Mao, Y. H. Lee, and B. C. Ng, "Statistical modeling of signal variation for propagation along a lift shaft," IEEE Antennas and Wireless Propagation Letters, vol. 9, no. 1, pp. 752-755, 2010.

[27] A. F. Molisch, L. J. Greenstein, and M. Shafi, "Propagation issues for cognitive radio," Proceedings of the IEEE, vol. 97, no. 5, pp. 787-804, 2009.

[28] L. Gao, Z. Zhong, B. Ai, and L. Xiong, "Estimation of the Ricean factor in K the high speed railway scenarios," in 2010 5th International ICST Conference on Communications and Networking in China, pp. 1-5, Beijing, China, 2010.

[29] M. Nakagami, "The $m$-distribution-a general formula of intensity distribution of rapid fading," in Statistical Methods in Radio Wave Propagation, W. C. Hoffman, Ed., pp. 3-36, Pergamon Press, New York, NY, USA, 1960.

[30] L. Rubio, J. Reig, and N. Cardona, "Evaluation of Nakagami fading behaviour based on measurements in urban scenarios," $A E U$ - International Journal of Electronics and Communications, vol. 61, no. 2, pp. 135-138, 2007.

[31] L. Liu, C. Tao, J. Qiu, T. Zhou, R. Sun, and H. Chen, "The dynamic evolution of multipath components in high-speed railway in viaduct scenarios: from the birth-death process point of view," in 2012 IEEE 23rd International Symposium on Personal, Indoor and Mobile Radio Communications (PIMRC), pp. 1774-1778, Sydney, NSW, Australia, 2012.

[32] M. Patzold, Mobile Radio Channels, Wiley Publishing, Hoboken, NJ, USA, 2012.

[33] T. Abbas and F. Tufvesson, "Line-of-sight obstruction analysis for vehicle-to-vehicle network simulations in a two-lane highway scenario," International Journal of Antennas and Propagation, vol. 2013, Article ID 459323, 9 pages, 2013.

[34] J. Yu, C. Li, K. Yang, and W. Chen, "GRG-MAPE and PCCMAPE based on uncertainty-mathematical theory for pathloss model selection," in 2016 IEEE 83rd Vehicular Technology Conference (VTC Spring), pp. 1-5, Nanjing, China, 2016.

[35] C. Li, J. Yu, K. Yang, and W. Chen, "Grey system theory application in model selection of channel modeling at $1.4 \mathrm{GHz}$," in 2016 International Conference on Wireless Communications, Signal Processing and Networking (WiSPNET), pp. 17451749, Chennai, India, 2016.

[36] J. Kunish and J. Pamp, "Wideband car-to-car radio channel measurements and model at $5.9 \mathrm{GHz}$," in 2008 IEEE 68th Vehicular Technology Conference, pp. 1-5, Calgary, BC, Canada, 2008.

[37] J. Deng, "Grey information space," Journal of Grey System, vol. 1, no. 2, 1989.

[38] P. Bello, "Characterization of randomly time-variant linear channels," IEEE Transactions on Communications Systems, vol. 11, no. 4, pp. 360-393, 1963.

[39] L. Cheng, B. Henty, and R. Cooper, "Multi-path propagation measurements for vehicular networks at $5.9 \mathrm{GHz}$," in 2008 IEEE Wireless Communications and Networking Conference, pp. 1239-1244, Las Vegas, NV, USA, 2008.

[40] I. Tan, W. Tang, K. Laberteaux, and A. Bahai, "Measurement and analysis of wireless channel impairments in DSRC vehicular communications," in 2008 IEEE International Conference on Communications, pp. 4882-4888, Beijing, China, 2008.

[41] I. Sen and D. W. Matolak, "Vehicle-vehicle channel models for the 5-GHz band," IEEE Transactions on Intelligent Transportation Systems, vol. 9, no. 2, pp. 235-245, 2008.

[42] A. F. Molisch and M. Steinbauer, "Condensed parameters for characterizing wideband mobile radio channels," International 
Journal of Wireless Information Networks, vol. 6, no. 3, pp. 133-154, 1999.

[43] M. Walter and M. Schnell, "The Doppler-delay characteristic of the aeronautical scatter channel," in 2011 IEEE Vehicular Technology Conference (VTC Fall), pp. 1-5, San Francisco, CA, USA, 2011.

[44] M. Walter, U. C. Fiebig, and A. Zajic, "Experimental verification of the non-stationary statistical model for V2V scatter channels," in 2014 IEEE 80th Vehicular Technology Conference (VTC2014-Fall), pp. 1-5, Vancouver, BC, Canada, 2014.

[45] M. Walter, D. Shutin, and U. C. Fiebig, "Delay-dependent Doppler probability density functions for vehicle-to-vehicle scatter channels," IEEE Transactions on Antennas and Propagation, vol. 62, no. 4, pp. 2238-2249, 2014. 


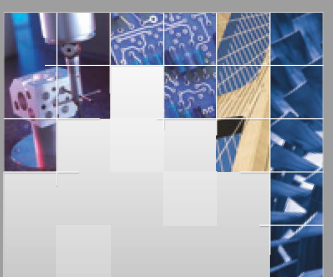

\section{Enfincering}
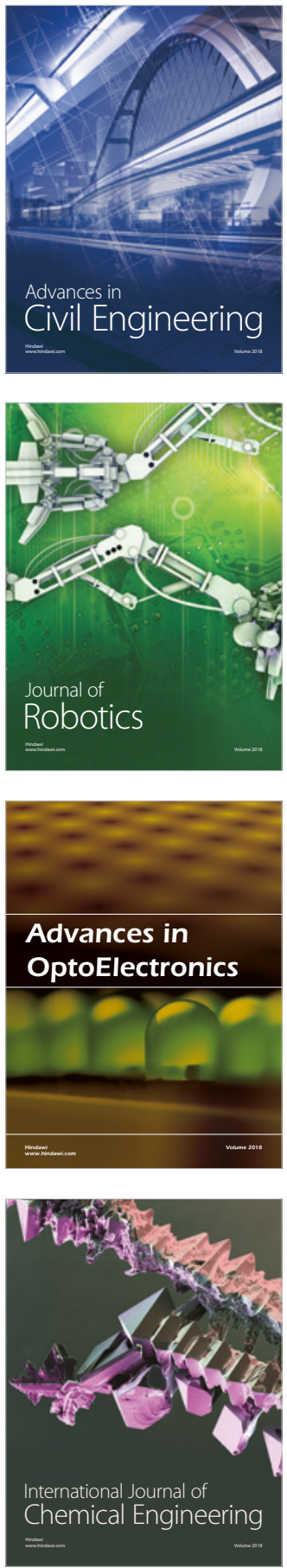

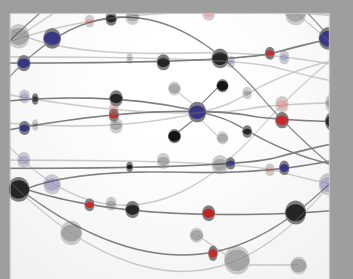

\section{Rotating \\ Machinery}

The Scientific World Journal

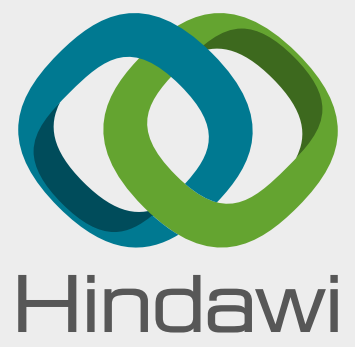

Submit your manuscripts at

www.hindawi.com
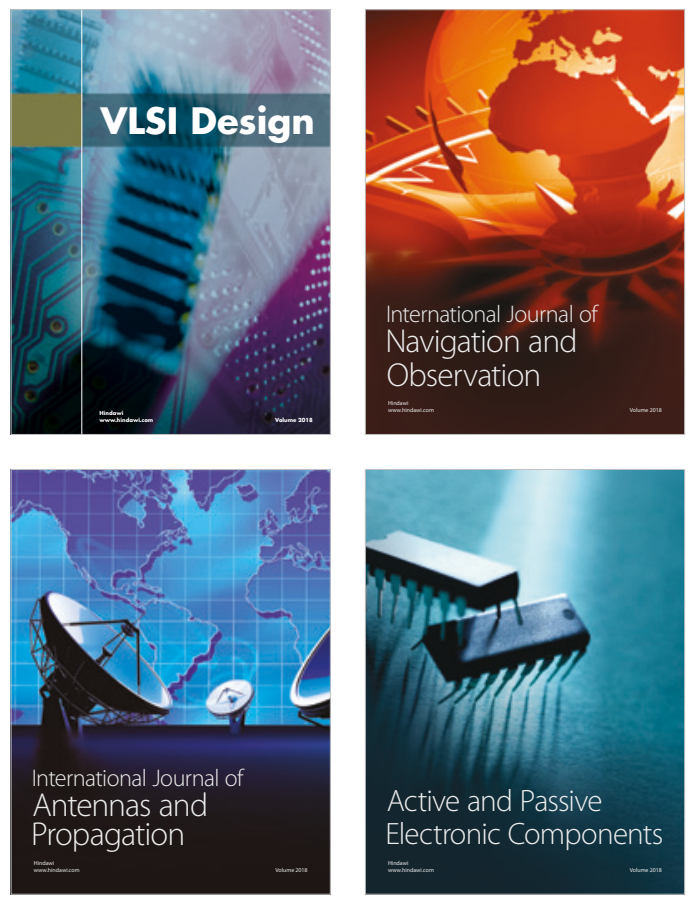
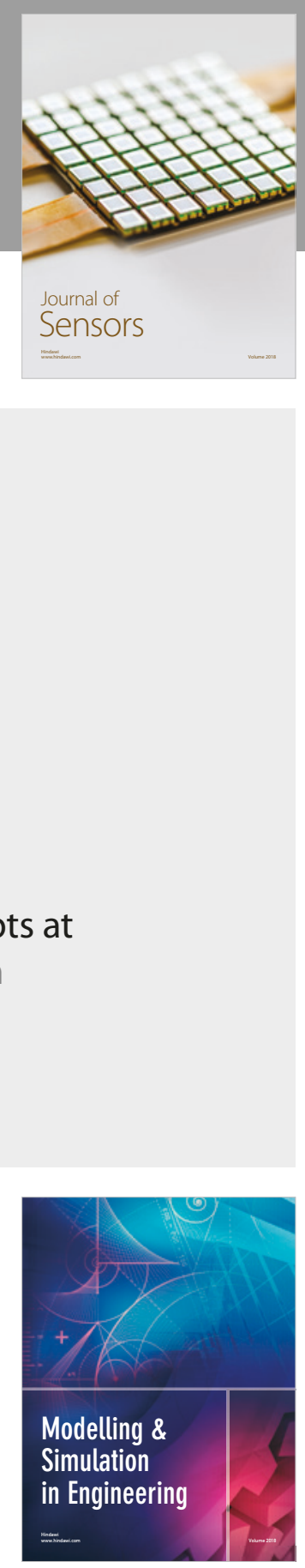

\section{Advances \\ Multimedia}
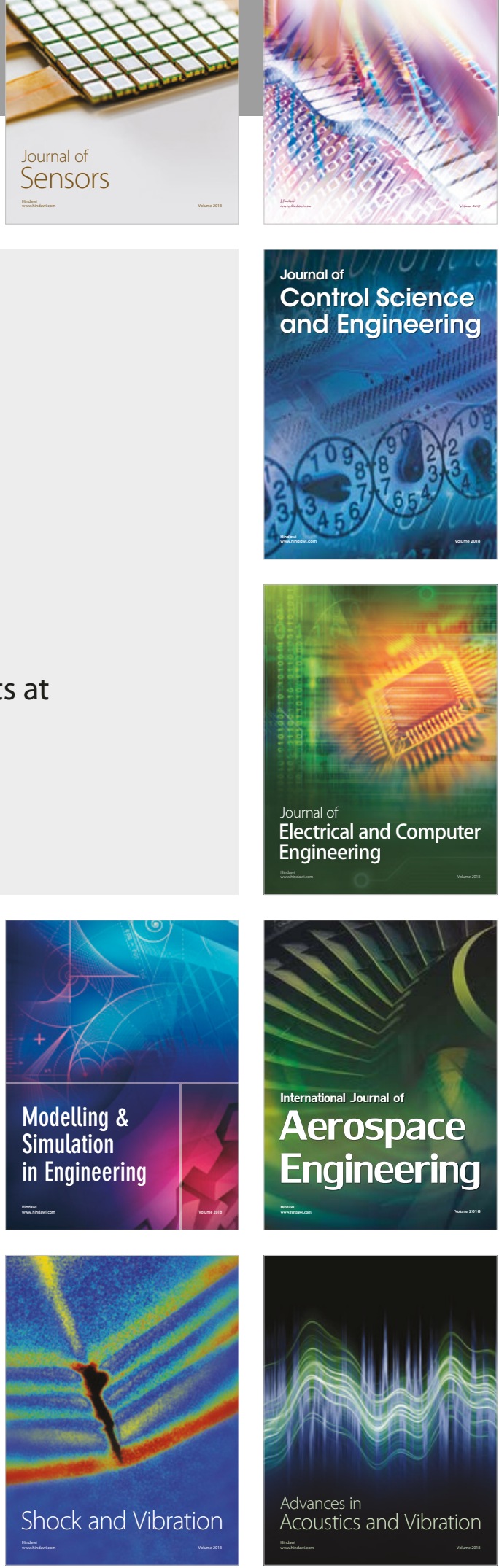